\title{
Dynamics of selenium uptake and metabolism of organic selenium species in the leaves and seeds of Brassica napus L.
}

\author{
Mervi M. Seppänen ${ }^{1}$, Nashmin Ebrahimi ${ }^{1}$, Juha Kontturi ${ }^{1}$, Helinä Hartikainen ${ }^{2}$, Isabel Lopez Heras ${ }^{3}$, Carmen Cámara ${ }^{3}$ \\ and Yolanda Madrid ${ }^{3}$ \\ ${ }^{1}$ Department of Agricultural Sciences,P.O. Box 27, Fl-00014 University of Helsinki,Finland \\ ${ }^{2}$ Department of Food and Environmental Sciences, P.O. Box 27, FI-00014 University of Helsinki,Finland \\ ${ }^{3}$ Department of Analytical Chemistry, Complutense University of Madrid ES-28040 Madrid, Spain \\ e-mail: mervi.seppanen@helsinki.fi
}

\begin{abstract}
The essential micronutrient selenium (Se) is retained better in animal and human tissues in its organic forms while nonprotein selenoamino acids, such as selenomethylselenocysteine (SeMetSeCys), are considered as functional organic Se species. We studied the ability of oilseed rape Brassica napus to metabolize inorganic selenate/selenite (SeVI/SelV) into various organic Se species, including SeMetSeCys. At $14 \mathrm{~d}$ after the inorganic Se application, 33\% of the Se had accumulated as selenomethionine (SeMet) and 60\% as SeVI, whereas no SeMetSeCys was detected. SeMet was the main organic Se species (53-94\%) in seeds. Brassica napus selenocysteine methyltransferase (SMT) protein sequence revealed a substitution typical of nonaccumulators explaining the low SeMetSeCys accumulation. Brassica napus absorbs rapidly inorganic Se and converts it into organic Se forms, mainly SeMet, that are suitable for augmenting animal feed and thereby supplementing the human food chain in Se-deficient countries. In contrast, Se biofortification did not result in accumulation of the more valuable SeMetSeCys.
\end{abstract}

Key words: selenomethionine, selenomethylselenocysteine, Se biofortification, Adenosine triphosphate sulphurylase, selenocysteine methyltransferase

\section{Introduction}

Selenium (Se) is an essential microelement for humans and animals. It is incorporated into the food chain as inorganic or organic Se compounds via crop plants. In regions of deficiency, such as Finland, the adequate intake of Se $\left(55 \mu \mathrm{g} \mathrm{d}^{-1}\right)$ by humans is ensured by the biofortification of crops by Se-augmented inorganic fertilizers.

Higher daily intake of Se (up to $200 \mu \mathrm{g} \mathrm{d}^{-1}$ ) may furnish additional health benefits, such as reduced cancer risk and an improved immune system (Rayman 2008b). Organic Se species are less toxic and better retained in human and animal tissues than inorganic Se (Rayman 2008b). Selenomethionine (SeMet) is the most abundant organic Se form in most plants and plant -derived food and, is the main species found in the seeds of Se-biofortified turnip Brassica rapa L. and oilseed rape B. napus L. subsp. oleifera (DC.) Metzg. plants (Seppänen et al. 2010). The nonprotein Se compound selenomethylselenocysteine (SeMetSeCys) and its $\gamma$-glutamyl derivative have antitumour properties in animals and are therefore considered to be valuable organic Se species (Rayman 2008a).

Due to their chemical similarity, selenate $(\mathrm{SeVI})$ and sulphur $(\mathrm{S})$ in the form of sulphate $\left(\mathrm{SO}_{4}\right)$ are taken up and assimilated by plants through the same $\mathrm{Se} / \mathrm{S}$ pathway. $\mathrm{SeVI}$ is taken up by high-affinity $\mathrm{SO}_{4}$ transporters in the roots (Sors et al. 2005a, White and Broadley 2009), whereas phosphate transporters are active in selenite (SelV) transport (Li et al. 2008). SeVI biotransformation is activated by adenosine triphosphate sulphurylase (ATPS), after which SeVI is reduced to SeIV by ATPS reductase. This reduction reaction may be the rate-limiting step of Se assimilation in plants (Pilon-Smits et al. 1999) that controls the flux throughout the Se/S assimilation pathway (Vauclare et al. 2002). SelV is further reduced to selenide by sulphite reductase and then incorporated into serine by cysteine synthetase to form selenocysteine (SeCys). SeMet is synthesized from SeCys and O-phosphohomoserine in multiple chemical reactions that involve enzymes, including cystathione $\gamma$-synthase, cystathione $\beta$-lyase and methionine synthase (Terry et al. 2000).

Plant species differ in their ability to take up and assimilate Se and can be divided into nonaccumulators, accumulators and an intermediate group of secondary accumulators that are also known as indicators (Bañuelos et al. 1997, Terry et al. 2000). The brassica species Chinese mustard Brassica juncea (L.) Czern. and B. napus belong to the group of Se secondary accumulators that can accumulate up to $1 \mathrm{mg} \mathrm{Se}^{-1} \mathrm{DM}$. The current understanding is that the Se-sensitive species incorporate SeCys and SeMet into proteins, whereas the Se-tolerant species have mechanisms to methylate these species into small nonprotein-forming amino acids such as SeMetSeCys (Brown and Shrift 1981, Sors et al. 2005b). The enzyme responsible for SeMetSeCys synthesis in the Se hyperaccumulator twogrooved milk-vetch Astragalus bisulcatus (Hook.) A. Gray is selenocysteine methyltransferase (SMT) (Neuhierl and Bock 1996, Ellis and Salt 2003). This enzyme shows a high degree of homology in accumulator and 
nonaccumulator plants, but it lacks SMT activity in nonaccumulator plants, which results in low or nondetectable levels of SeMetSeCys (Sors et al. 2009). In addition, a site-directed mutagenesis approach has shown that a crucial amino-acid substitution of alanine (Ala) to threonine ( $\mathrm{Thr}$ ) was responsible for the specific capacity to methylate SeCys (Sors et al. 2009). The seeds of Brassica napus are an important source of vegetable oil for humans, and the protein-rich meal is used as livestock feed. Our aim was to evaluate whether Brassica napus has the capacity to synthesize and accumulate SeMetSeCys together with other organic Se compounds and to reveal the bottlenecks in the accumulation of organic Se compounds in seeds.

\section{Materials and methods}

\section{Plant material and experimental conditions}

The winter genotype of oilseed rape plants (B. napus L. ssp. oleifera) were grown in a greenhouse (16/8-h day/ night lighting regime) in 1.5-I pots that contained a sand:quartz sand mixture ( $900 \mathrm{~g}$ sand:400 g quartz sand) to which the following plant nutrients (concentrations in $\mathrm{mM}$ ) $\mathrm{NH}_{4} \mathrm{NO}_{3} 222.9, \mathrm{CaHPO}_{4} 50.3, \mathrm{KH}_{2} \mathrm{PO}_{4} 67.1, \mathrm{MgSO}_{4}$ 65.0, $\mathrm{H}_{3} \mathrm{BO}_{3}$ 9.6, $\left(\mathrm{NH}_{4}\right)_{6} \mathrm{Mo}_{7} \mathrm{O}_{24} 0.5, \mathrm{CuSO}_{4} 0.8, \mathrm{ZnCl}_{2}$ 1.6, ethylenediaminetetraacetic acid (EDTA) 3.7, $\mathrm{MnCl}_{2} 4.7$, $\mathrm{Ni}\left(\mathrm{NO}_{3}\right)_{2} 0.9$ were added. The nutrients (totally $20 \mathrm{ml} \mathrm{pot}^{-1}$ ) were given in two applications, $2 / 3$ of the total quantity at sowing and the remaining (1/3) 2 weeks later. Five B. napus (cv. 4021B) seeds were sown in each pot, and after germination thinned to one plant per pot. Four weeks after sowing, two soil applications of Se $(0 \mu \mathrm{M}$ or 65 $\mu \mathrm{M}$ of sodium selenate $\left.\mathrm{Na}_{2} \mathrm{SeO}_{4}\right)$ and three leaf applications of $\mathrm{Se}\left(0 \mu \mathrm{M}\right.$ or $100 \mu \mathrm{M}$ of either $\mathrm{Na}_{2} \mathrm{SeO}_{4}$ or sodium selenite $\mathrm{Na}_{2} \mathrm{SeO}_{3}$ ) were carried out. In all, $25 \mathrm{ml}$ of water or $\mathrm{Na}_{2} \mathrm{SeO}_{4}$ solution equal to $0 \mu \mathrm{g}$ and $130 \mu \mathrm{g}$ Se per plant (65 $\mu \mathrm{M} \mathrm{Se}$ ) were added to the soil ( $\mathrm{Soil}_{0}$, Soil ${ }_{\mathrm{vl}}$ ); simultaneously, $3.75 \mathrm{ml}$ of water, $\mathrm{Na}_{2} \mathrm{SeO}_{4}$ or $\mathrm{Na}_{2} \mathrm{SeO}_{3}$ solutions were sprayed onto plant leaves in amounts equal to $0 \mu \mathrm{g}$ (Leaf ${ }_{0}$ ) or $30 \mu \mathrm{g}$ Se per plant (100 $\mu \mathrm{M}$ Se) of either

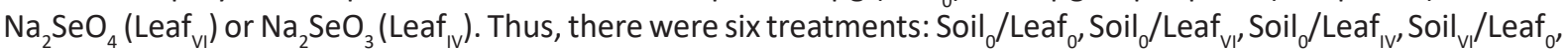
Soil $_{\mathrm{VI}} /$ Leaf $_{\mathrm{VI}}$ and Soil $\mathrm{V}_{\mathrm{V}} /$ Leaf $_{\mathrm{IV}}$. The pots were arranged in randomized complete block design (RCBD) in four blocks with four replications. Due to the four harvesting times $(6 \mathrm{~h}, 7 \mathrm{~d}, 14 \mathrm{~d}$ after inorganic Se application and matured plants), at each sampling time, one of the blocks was used. For the gene expression study, the newly developed leaves (fourth or fifth leaf) from two individual plants were harvested. For the Se speciation analysis, leaves of the same age from three individual plants were harvested. The remaining shoots were harvested for total Se analysis. Except for the last harvest, all plants were in the vegetative growth phase. The Se application levels were selected, based on previous studies, to obtain optimal Se accumulations without toxicity to the plants (Seppänen et al. 2010). SelV was applied only to the leaves, due to its low mobility in plants and its tendency to accumulate in the roots (Terry et al. 2000).

\section{Plant growth and harvest}

Plant development was recorded according to the Biologische Bundesanstalt, Bundessortenamt und Chemische Industrie (BBCH) scale, and the changes in leaf chlorophyll concentration of the marked leaves $(n=4$ or 5 per plant) were monitored weekly, using a SPAD-502 chlorophyll meter (Minolta Co. Ltd. (now Konica Minolta), Osaka, Japan). The uniformly aged upper leaves (fourth or fifth leaf) were harvested and rinsed for RNA and Se analysis $6 \mathrm{~h}, 7 \mathrm{~d}$ and $14 \mathrm{~d}$ after inorganic Se application and at harvest. At harvest, the plant height was measured and the main yield components (number of side branches and the number of siliques in the main branch and side branches) were counted.

\section{Gene expression analysis}

The RNA was extracted using TRI REAGENT (Applied Biosystems, Foster City, CA, USA) according to the manufacturer's instructions. Any possible DNA contamination was removed with DNase I digestion (SuperScript ${ }^{\mathrm{TM}}$ III CellsDirect complementary DNA (cDNA) Synthesis System; Invitrogen, Carlsbad, CA, USA). The cDNA was synthesized according to the manufacturer's instructions (SuperScript ${ }^{\mathrm{TM}}$ III reverse transcriptase, Invitrogen), using $1 \mu \mathrm{g}$ of total RNA and oligo (dT) ${ }^{18}$ primers. RNA that was complementary to the cDNA was removed by treatment with $1 \mu \mathrm{l}$ (2 units) of Escherichia coli (Migula) Castellani \& Chalmers RNase $\mathrm{H}$ and incubation at $37^{\circ} \mathrm{C}$ for $20 \mathrm{~min}$.

The primers were designed for S metabolism genes in B. napus. For the internal control, $\beta$-actin primers (F946-atcgtcctcagtggtggttc, R1049-gcgaccaccttgatcttcat) were designed according to GenBank sequence AF111812. APS1 (F373AACATGTCGGTGCCTATCGT, R482-AGGATAGCGACGGGATTACC), APS2 (F236-TCTCTTGCTTCACCCTTTGG, R341-CGGGTCAAGAACTCCATCTT) and APS3 (F188-TCCGGAAAGAGCTTGAGAAA, R289-GGCGAGTGTCAGTCATGAGA) primers were designed according to GenBank sequences U68218, EE463359 and EV120399, respectively, and the SMT (F279ATCTCCAGCGCTTCTTACCA, R394-TGCGAGCTTCACATGCTATT) primers to the EST JCVI_9670 (http://brassica.bbsrc. ac.uk/). A new set of primers (F385 5'ACCAGGCCACGATTCAGGGGT-3', R1216 5'-ACGTGAGTGAAGGTGGAGGAGGA-3') was designed to examine the potential Ala-184 to Thr replacement in the putative SMT protein sequence of $B$. napus. 
A 648-nucleotide-long sequence was obtained, translated into an amino-acid sequence (http://web.expasy.org/ translate/) and compared with its homologues in wild cabbage Brassica oleracea L. (AY817737.1) and A. bisulcatus (AJ131433.1), using Clustal W (http://www.genome.jp/tools/clustalw/).

Primer testing was done, using a $50-\mu$ polymerase chain reaction (PCR) that contained $0.5 \mathrm{U}$ of Taq polymerase (DyNAzyme II; Finnzymes OY, Espoo, Finland), 1 x buffer (DyNAzyme ${ }^{\mathrm{TM}}$ ), $0.2 \mu \mathrm{mol}$ of each primer, $200 \mu \mathrm{mol}$ of the deoxynucleotide phosphates (dNTPs) and $100 \mathrm{ng}$ of genomic DNA. The PCR was performed (Eppendorf Netheler-Hinz, Hamburg, Germany) under the following conditions: 5 min at $95^{\circ} \mathrm{C}$, followed by 35 cycles of $30 \mathrm{~s} \mathrm{at} 94^{\circ} \mathrm{C}$, $45 \mathrm{~s}$ at $57^{\circ} \mathrm{C}$ and $90 \mathrm{~s}$ at $72^{\circ} \mathrm{C}$. The PCR fragments were excised from the $1 \%$ Tris-acetate-EDTA (TAE) agarose gel, purified using the QIAquick gel extraction kit (Qiagen N.V., Hilden, Germany) and cloned into the PCR 2.1 -TOPO cloning vector (Invitrogen) according to the manufacturer's manual. The cloned fragments were sequenced at the Institute of Biotechnology (University of Helsinki) for verification of the amplification product.

Quantitative real-time polymerase chain reaction (qRT-PCR) analysis was carried out in a Light Cycler ${ }^{\circledR} 480$ RealTime PCR System (Roche Applied Science, Penzberg, Germany). A 20- $\mu$ l reaction contained $10 \mu$ l of DyNAmoTM (Finnzymes) SYBR ${ }^{\circledR}$ Green master mix, $0.5 \mu \mathrm{M}$ of each primer, $100 \mathrm{ng}$ of CDNA and $0.4 \mu \mathrm{l}$ of passive ROX dye. All primers were tested in a cDNA dilution series $(1,5,10,25,50$ and $100 \%)$, using the following program: $95^{\circ} \mathrm{C} 15$ min, $40 \times\left(94{ }^{\circ} \mathrm{C}\right.$ for $10 \mathrm{~s}, 59^{\circ} \mathrm{C}$ for $30 \mathrm{~s}$ and $72^{\circ} \mathrm{C}$ for $\left.30 \mathrm{~s}\right)$, with a melting curve at $95^{\circ} \mathrm{C}$ for $15 \mathrm{~s}, 60^{\circ} \mathrm{C}$ for $20 \mathrm{~s}$ and $95^{\circ} \mathrm{C}$ for $30 \mathrm{~s}$. The efficiency (E) values for the APS1, APS2 APS3, SMT and $\beta$-actin primers were 2.07, 1.92, 2.15, 2.11 and 2.03. The expression levels of the target genes were normalized, using $\beta$-actin as the reference gene, and the relative expression was calculated using the $2^{-{ }^{\Delta \Delta C T}}$ method (Livak and Schmittgen 2001).

\section{Selenium analysis}

The plant samples were dried overnight at $70{ }^{\circ} \mathrm{C}$ to determine the total concentration of Se. The soil samples were subjected to an acid mixture digestion $\left(\mathrm{HNO}_{3}, \mathrm{HClO}_{4}\right.$ and $\left.\mathrm{H}_{2} \mathrm{SO}_{4}\right)$, and all the Se forms were reduced to SelV by $\mathrm{HCl}$, which was subsequently chelated with ammonium pyrrolidine dithiocarbomate. The reduced Se was then extracted withy methyl isobutyl ketone. The analyses were executed with the electrothermal atomic absorption spectrometric (AAS) method (Kumpulainen et al. 1983), using a Zeeman spectrometer (model 5100; PerkinElmer Inc., Waltham, MA, USA) connected to a graphite furnace (model HGA 600; PerkinElmer) and equipped with an AS-60 autosampler (PerkinElmer). The accuracy of the measurement was confirmed by including an in-house reference sample for each set of samples.

Se speciation in the various samples was analysed with high-performance liquid chromatography-inductively coupled plasma-mass spectrometry (HPLC-ICP-MS) after extraction of the Se species, using ultrasonic probe-assisted enzymatic hydrolysis. About $0.05 \mathrm{~g}$ of fresh plant material and $3 \mathrm{ml}$ of Milli-Q water (Millipore Corp., Burlington, MA, USA) were placed into a tube with $20 \mathrm{mg}$ of Protease XIV (Sigma-Aldrich Corp., Steinheim, Germany) and sonicated at $40 \%$ ultrasound amplitude for $2 \mathrm{~min}$ in a Sonoplus ultrasonic homogenizer (Bandelin Electronic GmbH \& Co. KG, Berlin, Germany) that was equipped with a Titanium 3-mm-diameter microtip and fitted with a high-frequency generator of $2200 \mathrm{~W}$ at $20 \mathrm{kHz}$. The samples were filtered through a $0.22-\mu \mathrm{m}$ filter, and the extracts were analysed with HPLC-ICP-MS. Two chromatographic columns were used for the analysis to correctly identify the organic Se species. The first chromatographic column was a PRP X-100 anion-exchange column and the second a Shodex Asahipak column (Showa Denko K.K., Tokyo, Japan), both using combined size-exclusion and ion-exchange separation mechanisms. Standard stock solutions of $1000 \mathrm{mg} \mathrm{l}^{-1}$ of SeMet, SeMetSeCys and selenocystine (SeCys ${ }_{2}$ ) (Sigma) were prepared in ultrapure water $\left(18.2{\mathrm{M} \Omega \mathrm{cm}^{-1}}^{-1}\right.$ ) obtained from a Milli-Q water purification system (Millipore), and $3 \% \mathrm{HCl}$ was added to enhance the dissolution of SeCys ${ }_{2}$ and SeMetSeCys. Inorganic Se solutions (1000 $\mathrm{mg} \mathrm{l}^{-1}$ ) were prepared by dissolving $\mathrm{Na}_{2} \mathrm{SeO}_{3}$ and $\mathrm{Na}_{2} \mathrm{SeO}_{4}$ (Merck KGaA, Darmstadt, Germany) in Milli-Q water. The stock solutions were stored at $4{ }^{\circ} \mathrm{C}$.

\section{Statistical analyses}

The data were classified, based on the harvesting time, and each time was analysed separately. First, one-way analysis of variance (ANOVA) was carried out to reveal the differences between all the treatments and on which the tables presented here are formulated. In addition, to show the main effects and interactions between the soil and leaf applications of Se, a two-way ANOVA analysis was carried out. All statistical analyses were carried out, using SPSS software version 24 (IBM Corp., Armonk, NY, USA). Significantly different means between the treatments were analysed, using Tukey's test with $p \leq 0.05$. 


\section{Results}

\section{Plant growth and development}

Even very high Se accumulations in the leaves $\left(33 \mu \mathrm{g} \mathrm{Se}^{-1}\right.$, Table 1$)$ did not delay development of the plants, and no significant alterations in the (SPAD) values for leaf senescence were observed (data not shown). Fourteen days after application, the Se applied (to soil or leaves) lowered the DM content, but this reduction was transient, and the Se-induced impact on the seed yield was insignificant (data not shown). Furthermore, the Se addition did not alter the plant architecture, since the development of the yield components was similar in all treatments (data not shown).

Table 1. The concentrations of total Se in shoot and different Se species ( $\left.\mu \mathrm{g} \mathrm{g}^{-1} \mathrm{DM}\right)$ in Brassica napus plants at $6 \mathrm{~h}, 7$ days or 14 days after treatment with 0 or $130 \mu \mathrm{g} \mathrm{Se} \mathrm{plant}{ }^{-1}$ as Na$_{2} \mathrm{SeO}_{4}$ (SoilO and SoilVI,) in soil and 0 or $30 \mu \mathrm{g} \mathrm{Se} \mathrm{plant}^{-1}$, foliar spray of $\mathrm{Na}_{2} \mathrm{SeO}_{4}$ or $\mathrm{Na}_{2} \mathrm{SeO}_{3}$ (LeafO, LeafVI and LeafIV respectively). Selenomethionine (SeMet), selenomethyl selenocysteine (SeMeSeCys) and inorganic SeVI and SelV were detected. The recovery (R \%) was calculated by ratio of the sum of Se species to the total Se obtained by the acid digestion method. The number inside brackets is the percentage of different Se species from total Se.

\begin{tabular}{|c|c|c|c|c|c|c|}
\hline Treatments & $\begin{array}{c}\text { Total Se } \\
\text { in shoot } \\
\mu \mathrm{g} \mathrm{g}^{-1}\end{array}$ & SeMet & SeMeSeCys & SeVI & SelV & $\mathrm{R} \%$ \\
\hline \multicolumn{7}{|l|}{$6 \mathrm{~h}$} \\
\hline Soil $_{0} /$ Leaf $_{0}$ & $0.23^{f}$ & $0.39^{d}(54)$ & $0.00^{\mathrm{c}}(0)$ & $0.07^{d}(37)$ & $0.04^{\mathrm{cd}}(9)$ & $78^{c}$ \\
\hline Soil $_{0} /$ Leaf $_{\mathrm{v} 1}$ & $1.40^{\mathrm{e}}$ & $0.11^{d}(12)$ & $0.00^{c}(0)$ & $0.84^{d}(87)$ & $0.01^{d}(1)$ & $70^{d}$ \\
\hline Soil $_{0} /$ Leaf $_{\text {IV }}$ & $2.40^{\mathrm{d}}$ & $0.36^{d}(71)$ & $0.00^{c}(0)$ & $0.24^{\mathrm{d}}(2.5)$ & $0.09^{c}(18)$ & $21^{f}$ \\
\hline Soil $_{\mathrm{Vl}} /$ Leaf $_{0}$ & $18.72^{\mathrm{c}}$ & $2.83^{b}(15)$ & $0.8^{\mathrm{a}}(4)$ & $14.84^{\mathrm{a}}(80)$ & $0.00^{d}(0)$ & $99^{a}$ \\
\hline Soil $_{\mathrm{V} 1} /$ Leaf $_{\mathrm{vI}}$ & $20.85^{b}$ & $2.05^{\mathrm{c}}(16)$ & $0.26^{b}(2)$ & $10.06^{c}(80)$ & $0.26^{b}(2)$ & $61^{\mathrm{e}}$ \\
\hline Soil $_{\mathrm{VI}} /$ Leaf $_{\mathrm{IV}}$ & $23.04^{\mathrm{a}}$ & $5.76^{\mathrm{a}}(29)$ & $0.79^{a}(4)$ & $12.80^{\mathrm{b}}(64)$ & $0.60^{a}(3)$ & $87^{b}$ \\
\hline$\pm \mathrm{SE}$ & 0.13 & 0.20 & 0.02 & 0.27 & 0.02 & 1.31 \\
\hline Soil application & $p \leq 0.00$ & $p \leq 0.00$ & $p \leq 0.00$ & $p \leq 0.00$ & $p \leq 0.00$ & $p \leq 0.00$ \\
\hline Leaf application & $p \leq 0.00$ & $p \leq 0.00$ & $p \leq 0.00$ & $p \leq 0.00$ & $p \leq 0.00$ & $p \leq 0.00$ \\
\hline Soil*Leaf application & $p \leq 0.00$ & $p \leq 0.00$ & $p \leq 0.00$ & $p \leq 0.00$ & $p \leq 0.00$ & $p \leq 0.00$ \\
\hline \multicolumn{7}{|l|}{$7 d$} \\
\hline Soil $_{0} /$ Leaf $_{0}$ & $0.15^{d}$ & $0.08^{d}(49)$ & $0.00^{d}(0)$ & $0.04^{\mathrm{d}}(24)$ & $0.04^{d}(27)$ & $100^{b}$ \\
\hline Soil $_{0} /$ Leaf $_{\mathrm{v} 1}$ & $0.30^{\mathrm{d}}$ & $0.07^{d}(37)$ & $0.00^{d}(0)$ & $0.12^{d}(63)$ & $0.00^{e}(0)$ & $65^{d}$ \\
\hline Soil $_{0} /$ Leaf $_{\text {IV }}$ & $0.30^{d}$ & $0.14^{d}(41)$ & $0.00^{d}(0)$ & $0.03^{d}(9)$ & $0.17^{b}(49)$ & $115^{a}$ \\
\hline Soil $_{\mathrm{VI}} /$ Leaf $_{0}$ & $22.15^{\mathrm{a}}$ & $7.03^{\mathrm{a}}(33)$ & $0.23^{\mathrm{a}}(1)$ & $14.53^{\mathrm{a}}(66)$ & $0.11^{\mathrm{c}}(1)$ & $99 \mathrm{bc}$ \\
\hline Soil $_{\mathrm{VI}} /$ Leaf $_{\mathrm{v} 1}$ & $15.60^{\mathrm{b}}$ & $2.04^{c}(33)$ & $0.12^{\mathrm{b}}(2)$ & $4.00^{\mathrm{c}}(64)$ & $0.06^{d}(1)$ & $40^{\mathrm{e}}$ \\
\hline Soil $_{\mathrm{VI}} /$ Leaf $_{\mathrm{IV}}$ & $13.03^{c}$ & $5.54^{b}(46)$ & $0.06^{\mathrm{c}}(1)$ & $6.15^{b}(51)$ & $0.37^{\mathrm{a}}(3)$ & $93^{c}$ \\
\hline$\pm \mathrm{SE}$ & 0.16 & 0.13 & 0.00 & 0.19 & 0.01 & 1.94 \\
\hline Soil application & $p \leq 0.00$ & $p \leq 0.00$ & $p \leq 0.00$ & $p \leq 0.00$ & $p \leq 0.00$ & $p \leq 0.00$ \\
\hline Leaf application & $p \leq 0.00$ & $p \leq 0.00$ & $p \leq 0.00$ & $p \leq 0.00$ & $p \leq 0.00$ & $p \leq 0.00$ \\
\hline Soil*Leaf application & $p \leq 0.00$ & $p \leq 0.00$ & $p \leq 0.00$ & $p \leq 0.00$ & $p \leq 0.00$ & $p \leq 0.00$ \\
\hline \multicolumn{7}{|l|}{$14 \mathrm{~d}$} \\
\hline Soil $_{0} /$ Leaf $_{0}$ & $0.14^{d}$ & $0.06^{d}(46)$ & $0.00^{b}(0)$ & $0.05^{d}(36)$ & $0.02^{d}(17)$ & $98^{a b}$ \\
\hline Soil $_{0} /$ Leaf $_{\mathrm{v} 1}$ & $0.27^{d}$ & $0.16^{d}(59)$ & $0.00^{\mathrm{b}}(0)$ & $0.08^{d}(30)$ & $0.03^{d}(11)$ & $100^{a b}$ \\
\hline Soil $_{0} /$ Leaf $_{\text {IV }}$ & $0.63^{d}$ & $0.13^{d}(20)$ & $0.01^{\mathrm{b}}(2)$ & $0.05^{d}(8)$ & $0.46^{c}(70)$ & $103^{a}$ \\
\hline Soil $_{\mathrm{V} /} /$ Leaf $_{0}$ & $33.00^{\mathrm{a}}$ & $7.70^{\mathrm{a}}(29)$ & $0.00^{\mathrm{b}}(0)$ & $17.37^{\mathrm{a}}(64)$ & $1.93^{a}(7)$ & $82^{\mathrm{c}}$ \\
\hline Soil $_{\mathrm{V} v} /$ Leaf $_{\mathrm{v} 1}$ & $12.90^{c}$ & $4.02^{c}(32)$ & $0.25^{a}(2)$ & $8.00^{c}(65)$ & $0.13^{d}(7)$ & $96^{b}$ \\
\hline Soil $_{\mathrm{VI}} /$ Leaf $_{\mathrm{IV}}$ & $22.03^{b}$ & $5.81^{b}(32)$ & $0.00^{\mathrm{b}}(0)$ & $11.22^{\mathrm{b}}(61)$ & $1.28^{b}(7)$ & $83^{c}$ \\
\hline$\pm \mathrm{SE}$ & 0.15 & 0.15 & 0.00 & 0.27 & 0.04 & 2.21 \\
\hline Soil application & $p \leq 0.00$ & $p \leq 0.00$ & $p \leq 0.00$ & $p \leq 0.00$ & $p \leq 0.00$ & $p \leq 0.00$ \\
\hline Leaf application & $p \leq 0.00$ & $p \leq 0.00$ & $p \leq 0.00$ & $p \leq 0.00$ & $p \leq 0.00$ & $p \leq 0.00$ \\
\hline Soil*Leaf application & $p \leq 0.00$ & $p \leq 0.00$ & $p \leq 0.00$ & $p \leq 0.00$ & $p \leq 0.00$ & $p \leq 0.00$ \\
\hline
\end{tabular}

Numbers followed by different letters in the same column differ significantly at the $p \leq 5 \%$ by Tukey's test; $\mathrm{n}=3$. $P$ value of main effects and interaction between soil and leaf application has been reported. 


\section{Activation of gene expression}

Of the four S metabolism genes monitored, APS1 showed the greatest response in transcript accumulation (Fig. 1a). However, the levels of transcript accumulation of all the studied genes did not vary significantly between the treatments (Figs. 1a-d). The results indicate, however, that the soil Se application (Soil $/$ Leaf $_{0^{\prime}}$ Soil $_{\mathrm{IV}} /$ Leaf $_{\mathrm{VI}}$, Soil $_{\mathrm{IV}} /$ Leaf $_{\mathrm{IV}}$ ) tended to result in higher transcript accumulation of APS1 and APS2 than did the foliar Se application solely after $14 \mathrm{~d}$. Moreover, the foliar application of SeIV ( Leaf $_{\mathrm{IV}}$ ) seemed to result in more rapid transcript accumulation of all the studied genes.

$\square 6 \mathrm{~h} \square 7 \mathrm{~d} \square 14 \mathrm{~d}$

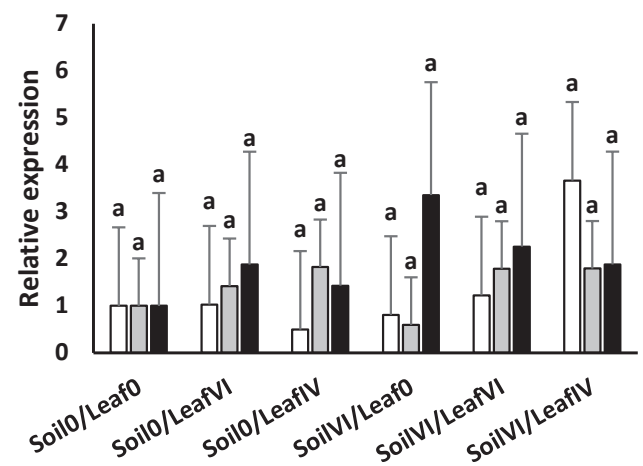

$\square 6 \mathrm{~h} \square 7 \mathrm{~d} \square 14 \mathrm{~d}$

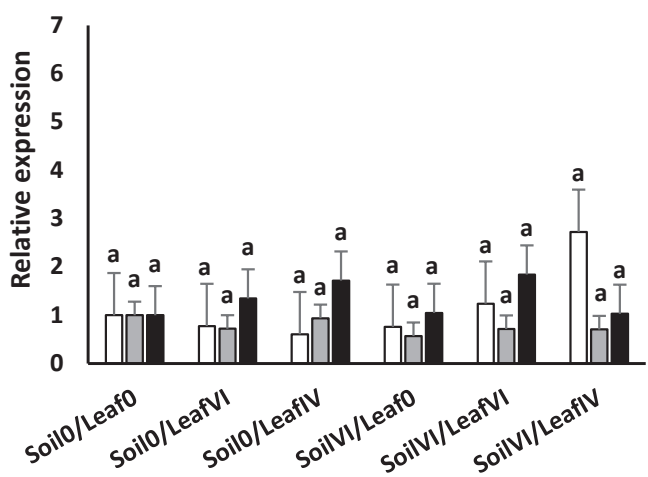

$\square 6 h \square 7 d \square 14$

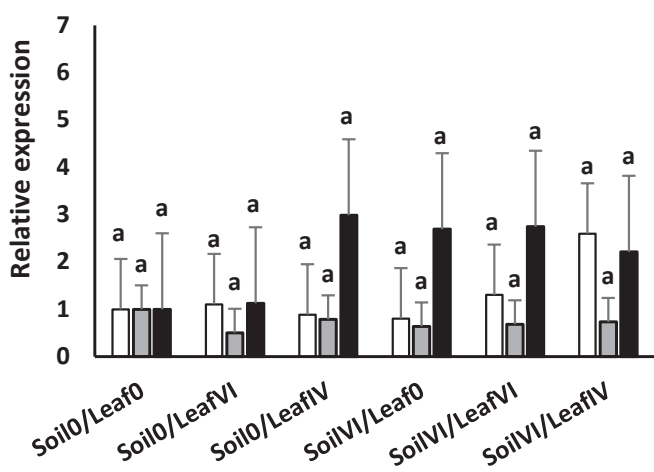

$\square 6 \mathrm{~h} \square 7 \mathrm{~d} \square 14 \mathrm{~d}$

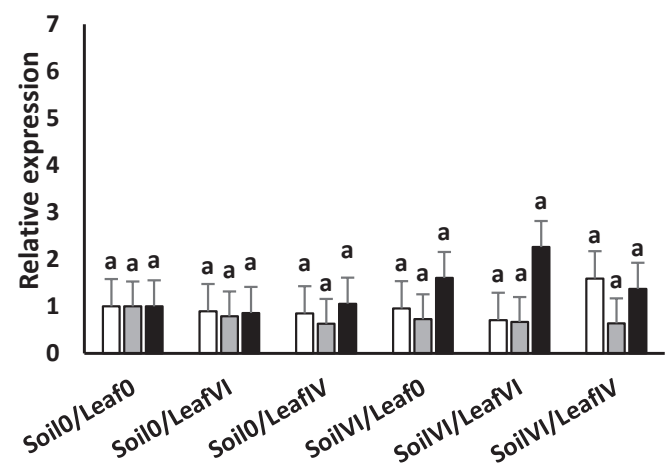

Fig. 1. Relative expression of a) APS1, b) APS2, c) APS3 and d) SMT genes at $6 \mathrm{~h}$ (white), $7 \mathrm{~d}$ (grey) and $14 \mathrm{~d}$ (black) after treatment with 0 or $130 \mu \mathrm{g} \mathrm{Se} \mathrm{plant}{ }^{-1}$ as $\mathrm{Na}_{2} \mathrm{SeO}_{4}$ in soil (SoilO and SoilVI,) and 0 or $30 \mu \mathrm{g}$ Se plant ${ }^{-1}$, foliar spray of $\mathrm{Na}_{2} \mathrm{SeO}_{4}$ or $\mathrm{Na}_{2} \mathrm{SeO}_{3^{\prime}}$ (LeafO, LeafVI and LeafIV respectively); mean $\pm \mathrm{SE} ; \mathrm{n}=2$

When the partial SMT homologue of $B$. napus was aligned with the corresponding sequences of the Se accumulator A. bisulcatus and the nonaccumulator B. oleracea (Fig. 2), the amino-acid alteration of Ala-184 to Thr, specific for Se nonaccumulators, was found in the $B$. napus sequence. The SMT protein sequence of $B$. napus showed closer homology with that of $B$. oleracea than with that of $A$. bisulcatus.

$$
\begin{aligned}
& \text { B.oleracea } \\
& \text { Astragalus } \\
& \text { B. napus }
\end{aligned}
$$

\section{B. oleracea Astragalus B. napus}

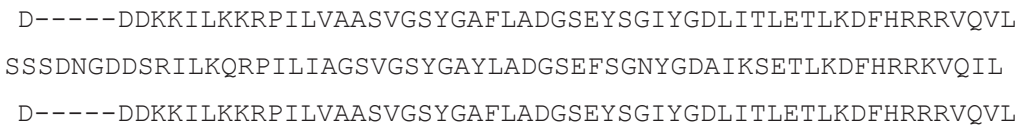

AESGADI IAFETIPNKLEAQAFAELLDEGVAKIPGWFSFNSKDGVNVVSGDS IKECIAIA ADSGVDLLAFEAVPNKLEAQAYADLLEEENI ITPAWFAFTSKDGNNVVSGDS IEECGS IA AESGADI IAFETIPNKLEAQ

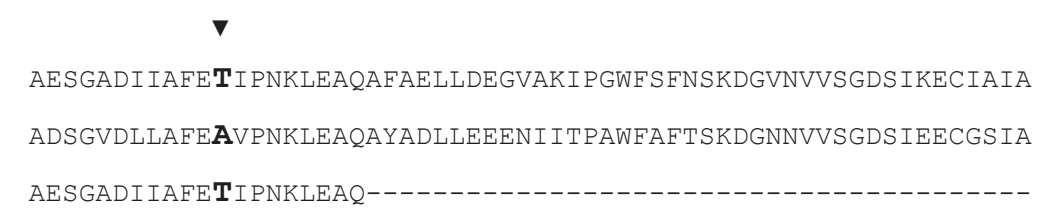

\section{B. oleracea \\ Astragalus \\ B. napus}

Fig. 2. Partial protein sequence alignment of selenomethyltransferase (SMT) of Brassica oleracea (GenBank: AY817737.1). Astragalus bisulcatus (AJ131433.1) and putative SMT sequence of Brassica napus. The Ala-184 residue unique to the Se accumulator and replacement by Thr residue in non-accumulators is marked in bold and indicated with a black arrowhead. 


\section{Identification of selenium species in leaves and seeds}

Analyses of the Se species revealed the dynamics of Se assimilation in the leaves of $B$. napus (Fig. 3). Six hours after SeVI application to the soil, $81 \%$ of the Se in the leaves was in the original inorganic form of SeVI, and this proportion decreased to $60 \%$ by $14 \mathrm{~d}$. Inorganic SeIV, in turn, was detected in the leaves after $7 \mathrm{~d}$, and the accumulation was substantial after $14 \mathrm{~d}$. This response was probably attributable to the intensive activation of the APS genes (Fig. 1) and accumulation of SelV as an intermediate product of Se assimilation. The concomitant increase in the total Se concentration of the leaves from 18.7 to $33.0 \mu \mathrm{g} \mathrm{g}^{-1}$ indicated that the soil still contained Se available for plant uptake (Table 1 ). The proportion of SeMet of $15 \%$ only $6 \mathrm{~h}$ after application increased to $33 \%$ at 14 $\mathrm{d}$, which indicated that the assimilation of Se into organic compounds is efficient in $B$. napus. The accumulation of SeMetSeCys detected as early as $6 \mathrm{~h}$ coincided with a two-fold increase in SMT expression (Fig. 1d). Although the SMT expression remained elevated, the SeMetSeCys content decreased to zero within $14 \mathrm{~d}$ (Fig. 3c, Table 1).

a)

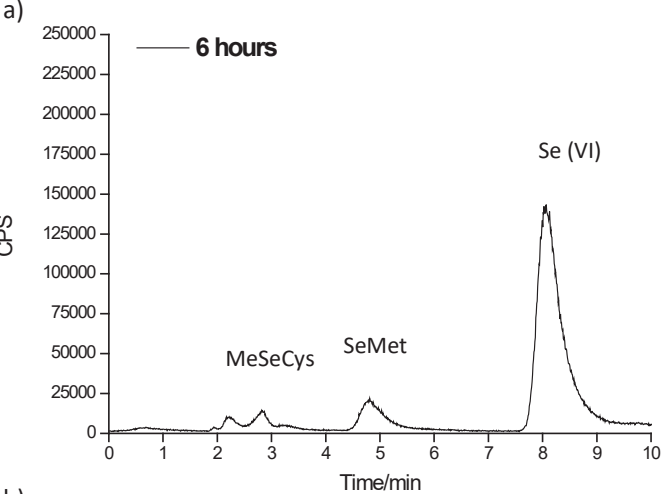

b)

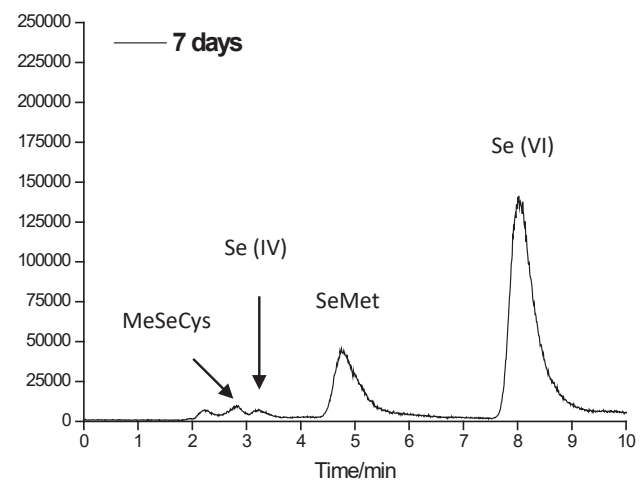

c)

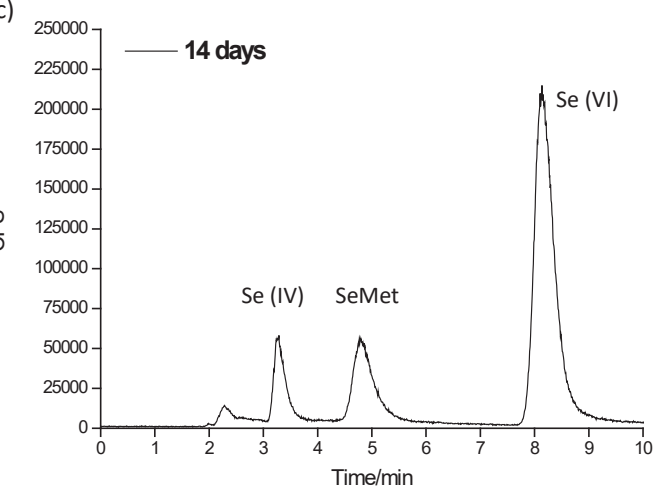

Fig. 3. Chromatographic profiles obtained by anion exchange with HPLC-ICP-MS for 80Se following enzymatic extraction of Brassica napus leaves at (a) $6 \mathrm{~h}$, (b) $7 \mathrm{~d}$ and (c) 14 $\mathrm{d}$ after treatment with $130 \mu \mathrm{g}$ Se plant ${ }^{-1}$ as $\mathrm{Na}_{2} \mathrm{SeO}_{4}$ in soil alone; $\mathrm{n}=3$

Foliar spraying of SeVI or SeIV resulted in the rapid accumulation of Se in the leaves. As expected, no changes in the main Se species were detected (Figs. $4 \mathrm{a}$ and b). The concentration of inorganic Se thereafter gradually became reduced as a result of the biotransformation of inorganic Se into organic forms of Se, especially into SeMet and its oxidation product selenomethionine Se oxide (SeOMet). The concentration of SelV in the respective foliar spraying treatment was highest at $14 \mathrm{~d}$ after Se treatment (Fig. 4b). The main Se species in seeds and meal, however, was SeMet, and only traces of SeOMet were detected (Figs. 5a and b).

\section{Accumulation of selenium species}

Se uptake was rapid. The Se concentration in the leaves for the Soil VI $_{\text {Leaf }}$ treatment only $6 \mathrm{~h}$ after the soil application was $18.7 \mathrm{\mu g} \mathrm{g}^{-1}$ (Table 1). The total Se concentration in the shoots found for the Soil ${ }_{\mathrm{VI}} /$ Leaf $_{\mathrm{IV}}$ treatment 
increased more rapidly than for the Soil /Leaf $_{\mathrm{v} /}$ treatment. Furthermore, the SeIV resulted in a more rapid biotransformation of inorganic Se species into SeMet than did SeVI, and this occurred at a level that was higher in the Leaf treatments than for their Leaf $_{\mathrm{V} 1}$ counterparts, irrespective of the Se application rate to the soil. Furthermore, the biotransformation of SeMet in the SelV-treated plants was more rapid than in the SeVI-treated plants. The concentration of SeMet was higher in the Leaf ${ }_{I V}$ treatment plants than in the Leaf ${ }_{V I}$ plants, irrespective of the application rate. The SeMet concentration decreased in the plants supplied only with foliar Se additions. This response was probably caused by a dilution effect resulting from the increase in biomass, which lowered the concentrations of Se available for SeMet biosynthesis.
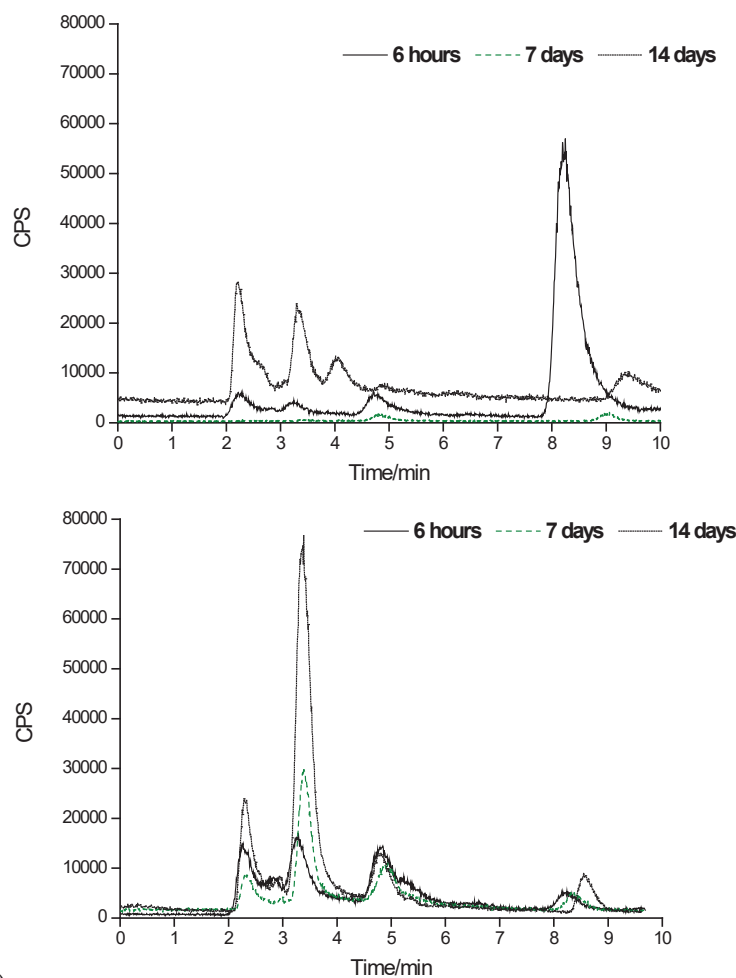

a)

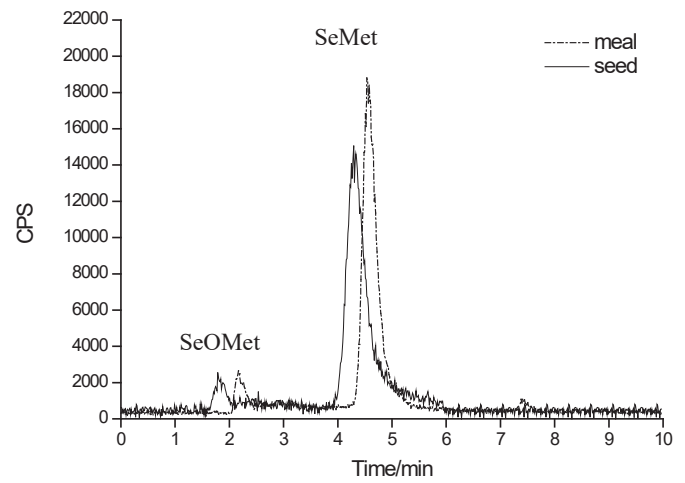

b)

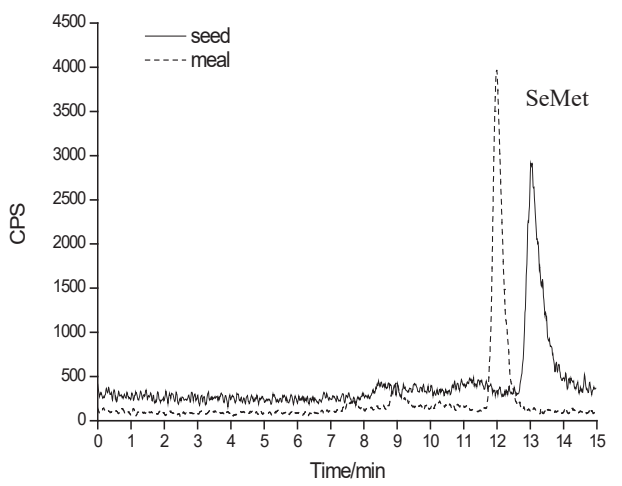

Fig. 4. Chromatographic profiles obtained by anion exchange HPLC-ICP-MS for $80 \mathrm{Se}$ following enzymatic extraction of the Brassica napus leaves at $6 \mathrm{~h}, 7 \mathrm{~d}$ and $14 \mathrm{~d}$ after foliar spray with a) $30 \mu \mathrm{g}$ Se plant ${ }^{-1}$ as $\mathrm{Na} 2 \mathrm{SeO} 4$ and b) $30 \mu \mathrm{g}$ Se plant ${ }^{-1}$ as $\mathrm{Na}_{2} \mathrm{SeO}_{3}$ respectively; $n=3$

Fig. 5. Chromatographic profiles obtained by (a) anion exchange HPLC-ICP-MS and (b) size exclusion anion exchange HPLC-ICP-MS for 80Se following enzymatic extraction of Brassica napus meal and seeds from plants after treatment with $130 \mu \mathrm{g}$ Se plant ${ }^{-1}$ as $\mathrm{Na}_{2} \mathrm{SeO}_{4}$ in soil and $30 \mu \mathrm{g}$ Se plant ${ }^{-1}$, foliar spray of $\mathrm{Na}_{2} \mathrm{SeO}_{4} ; \mathrm{n}=3$ 
The Se accumulation was generally lower in the plants that were only supplied with foliar Se, compared with those plants in which it was applied to the soil (Table 1). Foliar spraying seemed to interfere both with the uptake of inorganic Se and its conversion into SeMet. The inorganic Se and SeMet concentrations were lower in the plants that received the combined foliar and soil application than in those in which Se was added only to the soil (Soil $/$ Leaf ${ }_{0}$ ). This was clearly seen in the SeMet concentration $7 \mathrm{~d}$ after the Se application (Table 1). The expression of the APS1 homologue gene in the plants treated with foliar Se peaked earlier at $7 \mathrm{~d}$ than at $14 \mathrm{~d}$ for those $B$. napa supplied with Se to the soil (Fig. 1a). The APS1 expression in the Soil / /Leaf treatment decreased radically, which may partly explain their lower SeMet concentrations (Table 1). The accumulation of SelV in these treatments was also slower than that of SeVI and its peak concentration in the Soil ${ }_{0} /$ Leaf ${ }_{\mathrm{IV}}$ plants, which was measured after $14 \mathrm{~d}$.

The chromatograms show that SeMet was the main organic Se compound (Figs. 3 and 4) and that its proportion of all Se species varied significantly between treatments and sampling times, the range being 12-71\% (Table 1). The accumulation of SeMetSeCys (2-4\% of the total Se) was detected in the leaves $6 \mathrm{~h}$ after the Se application to the soil, but its concentration diminished at the two subsequent time points. The expression of SMT homologue

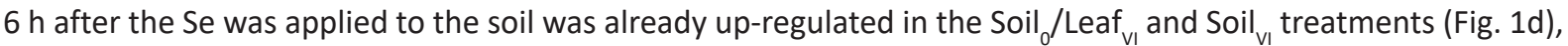
but the expression levels clearly did not correlate with the (detected) SeMetSeCys concentrations (Table 1).

Se application to the soil resulted in high accumulations of total Se and SeMet in the seeds and the dried meal (Table 2), with up to $94 \%$ of the Se in the meal being in the form of SeMet. Although the concentrations of inorganic Se species were high in the leaves, inorganic SeVI and SeIV were not detected in the seeds.

Table 2. The concentrations of total Se and different Se species ( $\mu \mathrm{g} \mathrm{g}^{-1} \mathrm{DM}$ ) in Brassica napus seeds and meal in mature plants after treatment with 0 or $130 \mu \mathrm{g} \mathrm{Se} \mathrm{plant}^{-1}$ as Na $_{2} \mathrm{SeO}_{4}$ (SoilO and SoilVI) in soil and 0 or $30 \mu \mathrm{g} \mathrm{Se} \mathrm{plant}{ }^{-1}$, foliar spray of $\mathrm{Na}_{2} \mathrm{SeO}_{4}$ or $\mathrm{Na}_{2} \mathrm{SeO}_{3}$, (LeafO, LeafVI and LeafIV respectively). Selenomethionine (SeMet) and inorganic SeVI were detected. The recovery $(\mathrm{R} \%)$ was calculated by ratio of the sum of Se species to the total Se obtained by the acid digestion method. The number inside brackets is the percentage of different Se species from total Se.

\begin{tabular}{|c|c|c|c|c|}
\hline Treatment & $\begin{array}{c}\text { Total Se in seed/ } \\
\text { meal }\end{array}$ & SeMet & SeVI & $\mathrm{R} \%$ \\
\hline \multicolumn{5}{|l|}{ Seeds } \\
\hline Soil $_{0} /$ Leaf $_{0}$ & $0.46^{d}$ & $0^{e}(0)$ & $0.0^{a}(0)$ & $0^{\mathrm{e}}$ \\
\hline Soil $_{0} /$ Leaf $_{\mathrm{vI}}$ & $0.29^{d}$ & $0.17^{d}(59)$ & $0.0^{a}(0)$ & $59 b c$ \\
\hline Soil $_{0} /$ Leaf $_{\text {IV }}$ & $0.34^{d}$ & $0.21^{d}(62)$ & $0.0^{a}(0)$ & $62^{b}$ \\
\hline Soil $_{\mathrm{vl}} /$ Leaf $_{0}$ & $5.56^{a}$ & $2.92^{b}(53)$ & $0.0^{a}(0)$ & $53^{d}$ \\
\hline Soil $_{\mathrm{vl}} /$ Leaf $_{\mathrm{VI}}$ & $5.05^{b}$ & $3.38^{a}(67)$ & $0.0^{a}(0)$ & $67^{a}$ \\
\hline Soil $_{\mathrm{Vl}} /$ Leaf $_{\mathrm{IV}}$ & $4.41^{c}$ & $2.40^{c}(55)$ & $0.0^{a}(0)$ & $55^{c d}$ \\
\hline$\pm \mathrm{SE}$ & 0.09 & 0.05 & n.s. & 0.02 \\
\hline Soil application & $p \leq 0.00$ & $p \leq 0.00$ & n.s. & $p \leq 0.00$ \\
\hline Leaf application & $p \leq 0.00$ & $p \leq 0.00$ & n.s. & $p \leq 0.00$ \\
\hline $\begin{array}{l}\text { Soil*Leaf } \\
\text { application }\end{array}$ & $p \leq 0.00$ & $p \leq 0.00$ & n.s. & $p \leq 0.00$ \\
\hline \multicolumn{5}{|l|}{ Meal } \\
\hline Soil $_{0} /$ Leaf $_{0}$ & $0.07^{c}$ & $0.04^{c}(66)$ & $0.006^{a}(9)$ & $79^{b c}$ \\
\hline Soil $_{0} /$ Leaf $_{\mathrm{VI}}$ & $0.27^{c}$ & $0.20^{c}(71)$ & $0.000^{b}(0)$ & $70^{c}$ \\
\hline Soil $_{0} /$ Leaf $_{\text {IV }}$ & $0.17^{c}$ & $0.16^{c}(93)$ & $0.000^{b}(0)$ & $93^{a}$ \\
\hline Soil $_{\mathrm{vl}} /$ Leaf $_{0}$ & $4.40^{b}$ & $3.72^{b}(85)$ & $0.003^{a b}(1)$ & $84^{a b}$ \\
\hline Soil $_{\mathrm{VI}} /$ Leaf $_{\mathrm{VI}}$ & $5.34^{\mathrm{a}}$ & $4.63^{a}(87)$ & $0.000^{b}(0)$ & $86^{a b}$ \\
\hline Soil $_{\mathrm{VI}} /$ Leaf $_{\mathrm{IV}}$ & $5.23^{a}$ & $4.74^{a}(91)$ & $0.000^{b}(0)$ & $90 \mathrm{ab}$ \\
\hline$\pm \mathrm{SE}$ & 0.08 & 0.09 & 0.00 & 0.04 \\
\hline Soil application & $p \leq 0.00$ & $p \leq 0.00$ & $p \leq 0.24$ & $p \leq 0.01$ \\
\hline Leaf application & $p \leq 0.00$ & $p \leq 0.00$ & $p \leq 0.00$ & $p \leq 0.00$ \\
\hline $\begin{array}{l}\text { Soil*Leaf } \\
\text { application }\end{array}$ & $p \leq 0.00$ & $p \leq 0.00$ & $p \leq 0.25$ & $p \leq 0.01$ \\
\hline
\end{tabular}

Numbers followed by different letters in the same column differ significantly at the $p \leq 5 \%$ by Tukey's test; $\mathrm{n}=3 ; p$ value of main effects and interaction between soil and leaf application has been reported; $n$.s. = non-significant 
M.M. Seppänen et al. (2018) 27: 38-49

The two-way ANOVA results showed that apart from significant interaction between the soil and leaf applications, both the main effects on total Se accumulation and the concentration of Se species in the leaves were also significant $(p \leq 0.00$ ) (Table 1$)$. In the case of meal, only the main effect of the soil application on the SeVI concentration was not significant $(p \leq 0.24)$, and no significant interaction between the soil and leaf applications was shown $(p \leq 0.25)$ (Table 2$)$.

\section{Discussion}

Reports on the effects of Se on plant growth and yield are somewhat contradictory. The Se added in the present experiment improved the seed set in accordance with previous reports on B. napus (Lyons et al. 2009, Ebrahimi et al. 2015). In field experiments, however, no increase in Brassica yields as a response to Se application has been reported (Lyons et al. 2009, Seppänen et al. 2010). However, some studies showed that low concentrations of Se in other plant species enhance plant growth and DM accumulation (Hartikainen and Xue 1999, Xue et al. 2001, Ebrahimi et al. 2015) or do not affect either parameter (Hartikainen et al. 1997, Djanaguiraman et al. 2010). Recently Li et al. (2018) reported that significant increase in turnip (B. rapa) DM was obtained with $0.5 \mathrm{Se} \mathrm{mg} \mathrm{kg}^{-1}$ soil as SeVI or SelV, which is higher than our soil application as SeVI. They also showed that the foliar application of SeVI and SelV had no significant effect on plants biomass.

Se concentrations above a threshold level can reduce growth without any symptoms of toxicity (Terry et al. 2000, Lyons et al. 2005). In our experiment, transient reductions in the range of 3-28\% in leaf DM accumulation were detected $14 \mathrm{~d}$ after the Se application coincided with a rapid Se accumulation in plant tissue and activation of its biotransformation into organic compounds. Thus, the growth retardation may have been attributable to metabolic disturbance caused by accumulated inorganic Se and its conversion into organic compounds, such as SeMet. In this experiment, SelV was more rapidly biotransformed into selenoamino acids than reported earlier (Sors et al. 2005a) for SeVI, and it also caused a more severe reduction in the growth of $B$. napus than did SeVI.

The main form of Se that accumulated in the secondary accumulator white princesplume Stanleya albescens M.E. Jones was Se-cystathione (Se-Cyst), a metabolic intermediate between SeCys and SeMet (Freeman et al. 2010). The results of our SMT gene sequencing and Se speciation analysis showed that the Se metabolism of $B$. napus resembles that of the secondary accumulators. In our experiments, up to $4 \%$ of the Se was found as SeMetSeCys in B. napus, $6 \mathrm{~h}$ to $7 \mathrm{~d}$ after the Se application, similar to that in milk-vetch Astragalus L. species (Sors et al. 2005b). The moderate accumulation of SeMetSeCys in B. napus indicates that the incorporation of excess Se into nonprotein amino acids is not efficient, so the transient growth retardation indicated that the tissue Se concentration had exceeded a Se toxicity threshold value.

The predicted partial SMT amino-acid sequence of protein B. napus revealed homology with nonaccumulating species, including: Drummond's milk-vetch Astragalus drummondii Douglas ex Hook., groundplum milk-vetch Astragalus crassicarpus Nutt. and freckled milk-vetch Astragalus leptocarpus Torr. \& A. Gray in having a tyrosine (Tyr) residue at position 148 instead of phenylalanine (Phe) (Sors et al. 2009). Moreover, the Ala-184-Thr substitution indicates that the SMT enzyme in B. napus has no substrate specificity for SeCys, but does have a dual SMT/HMT (homocysteine S-methyltransferase HMT EC 2.1.1.10) function with the ability to methylate both SeCys and HoCys (homocysteine). Astragalus bisulcatus SMT (AbSMT) shows a high level of homology with the coding region of the HMT enzyme, but due to the presence of Ala at position 184, it appears to be specific for the methylation of SeCys and to lack the ability to methylate HoCys (Sors et al. 2009). Flowering plants have an S-methylmethionine (SMM) cycle in which SMM is synthesized from Met, converted to S-adenosylmethionine (AdoMet) and back again to Met, with the last conversion step being catalysed by HMT (Mudd and Datko 1990, Ranocha et al. 2001). The dual SMT/HMT function in the nonaccumulator species may provide an alternative pathway for the methylation of SeCys and HoCys and play a unique role in plant Se and S metabolism (Lyi et al. 2007). The dual SMT/HMT function in B. napus may have contributed to the low level of SeMetSeCys and the high accumulation of SeMet that was observed in this study and also in our previous study of SeMet (Seppänen et al. 2010). It should also be noted that SeCys is a substrate for SeMetSeCys synthesis and was not detected after the Se application when significant amounts of SeMet were synthesized in the leaf tissue.

A 1.5-2-fold increase in the accumulation SMT transcription was detected after the application of SeVI to soil in the present study. Lyi et al. (2007) showed that the expression of Brassica oleracea SMT (BoSMT) in Brassica oleracea responded to the applied, SeVI whereas the highly homologous Brassica oleracea HMT (BoHMT) was up-regulated by the Se status and to a lesser extent by Met, SMM, HoCys or cadmium. In rockcresses Arabidopsis (DC.) 
Heynh., the HMT2 gene was activated by SeVI (Zhang et al. 2006), which suggests a role in the detoxification of SeCys via methylation to prevent its incorporation into proteins (LeDuc et al. 2004). Methylated SeCys, however, was not detected in these plants. The accumulated organic Se species in our experiment (SeMet, SeOMet and SeMetSeCys), were the same compounds that had accumulated in wheat Triticum L. during a short 24-h feeding regime with SeVI or SelV (Li et al. 2008). No SeCys or methylated SeCys was detected in SeVI-treated B. napus plants, which suggests that neither the synthesis nor the methylation of SeCys is the main detoxification mechanism, nor is it plausible that these molecules are so labile that they are lost during extraction and detection by HPLC-ICP-MS.

ATPS is a key enzyme of the $\mathrm{SO}_{4}$ assimilation pathway in plants (Leustek and Saito 1999) and can also be activated by SeVI (Renosto et al. 1993). The importance of ATPS and SMT activities for Se metabolism has been verified, using transgenic approaches (Pilon-Smits et al. 1999, LeDuc et al. 2004, LeDuc et al. 2006). Our experiment showed

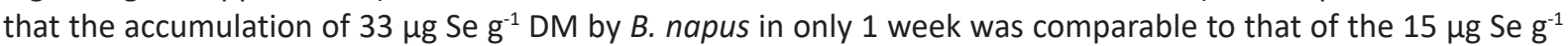
dry weight (DW) by S. albescens in the same time interval (Zhang et al. 2006). APS1 responded most to the Se applied in our experiments. The amount and chemical form of the Se applied and the feeding time varied in these expression studies, which can in turn explain why different isoforms of the APS genes were activated in the various experiments (Zhang et al. 2006, Hoewyk et al. 2008, Freeman et al. 2010).

The soil SeVI was rapidly taken up and assimilated as SeMet throughout our experiment, and the high proportion of Se in SeMet increased, whereas the quantities of inorganic SeVI decreased. When either SeVI or SelV was applied to the leaves, substantially less SeMet accumulated, while SeOMet accumulated only in the plants undergoing the foliar Se treatment. The study by Li and colleagues (Li et al. 2008) showed that a short 24-h feeding period for wheat with SeVI and SeIV resulted in low accumulation of SeMet, SeOMet and SeMetSeCys in the roots. The foliar application of SeVI and SeIV in the present study seemed to interfere with the root SeVI uptake to a similar extent as that found for the SelV applied to the soil, which suppressed SeVI uptake by wheat roots (Zhang et al. 2006).

Up to $67 \%$ and $94 \%$ of the total Se was found as SeMet in the seeds and meal of B. napus, respectively, similar to our findings in a previous field experiment (Seppänen et al. 2010). In the current experiment, the Se concentrations of the seeds were 5 - to 10 -fold higher than those we obtained in the previous field experiment, yet the proportion of SeMet in the total Se remained high. This indicates that the synthesis of SeMet in B. napus is efficient and that seeds are a strong sink for SeMet. Whether SeMet in seeds is incorporated in storage proteins or exists as a free amino acid is not known.

In the Leaf ${ }_{\mathrm{IV}}$ and Leaf ${ }_{\mathrm{VI}}$ treatments, traces of SeOMet were detected in the seeds and meal. SeOMet is an oxidation product of SeMet and can be formed during sampling, storage and sample treatment. One of the main problems related to Se speciation is the lack of available compound standards, and coelution is also a problem. The proper identification of peaks requires the use of at least two chromatographic columns with different separation mechanisms, and two different chromatographic columns were indeed used in the present experiment. By these combined means, the presence of both SeOMet and SeMet was unambiguously confirmed.

We conclude that all SeVI applications to the soil activate the S assimilation pathway in B. napus, which rapidly takes up Se within $6 \mathrm{~h}$. The intensive Se uptake causes a transient growth retardation, activation of Se detoxification and modest synthesis of nonprotein SeMetSeCys. The SMT enzyme in B. napus carries an Ala-184-Thr mutation, which causes dual SMT/HMT functioning of the enzyme, and this may explain the low accumulation of SeMetSeCys. The main organic Se compound that accumulated in the leaves and seeds was SeMet, whereas SeCys, the substrate for SeMetSeCys synthesis, was not detected. A transient accumulation of methylated Se compounds indicates that the volatilization of Se compounds may be activated and function as a detoxification mechanism in B. napus.

\section{Acknowledgements}

The Emil Aaltonen Foundation, Aino and August Tiura Foundation, Maj and Tor Nessling Foundation, Raisio Agro Ltd. and Yara Suomi Ltd. are acknowledged for their financial support in Finland. The Complutense University group thanks the Spanish Commission of Science and Technology (CTQ-2011-22732) and the Comunidad Autonoma de Madrid (Spain) and European funding from the FEDER programme (project S2009/AGR-1464, ANALISYC-II) for their support. COST FA0905 (Mineral-improved crop production for healthy food and feed) is acknowledged for providing the platform for collaboration between the laboratories. 


\section{References}

Bañuelos, G.S., Ajwa, H.A., Mackey, M., Wu, L., Cook, C., Akohoue, S. \& Zambruski, S. 1997. Evaluation of different plant species used for phytomediation of high soil selenium. Journal of Environmental Quality 26: 639-646. https://doi.org/10.2134/ jeq1997.00472425002600030008x

Brown, T.A. \& Shrift, A. 1981. Exclusion of selenium from proteins in selenium-tolerant Astragalus species. Plant Physiology 67: 1951-1953. https://doi.org/10.1104/pp.67.5.1051

Djanaguiraman, M., Prasad, P.V.V. \& Seppänen, M. 2010. Selenium protects sorghum leaves from oxidative damage under high temperature stress by enhancing antioxidant defence system. Plant Physiology and Biochemistry 48: 999-1007. https://doi. org/10.1016/j.plaphy.2010.09.009

Ebrahimi, N., Hartikainen, H., Simojoki, A., Hajiboland, R. \& Seppänen, M.M 2015. Dynamics of dry matter and selenium accumulation in oilseed rape (Brassica napus L.) in response to organic and inorganic selenium treatments. Journal of Agricultural and Food Science 24: 104-117.

Ellis, D.R. \& Salt, D.E. 2003. Plants, selenium and human health. Current Opinion of Plant Biology 6: 273-279. https://doi. org/10.1016/S1369-5266(03)00030-X

Freeman, J.L., Tamoki, M., Stushnoff, C., Quinn, C.F., Cappa, J.J., Devonshire, J., Fakra, S.C., Marcus, M.A., McGrath, S.P., Van Hoewyk, D. \& Pilon-Smits, E.A.H. 2010. Molecular mechanisms of selenium tolerance and hyperaccumulation in Stanleya pinnata. Plant Physiology 153: 1630-1653. https://doi.org/10.1104/pp.110.156570

Hartikainen, H., Ekholm, P., Piironen, V., Xue, T., Koivu, T. \& Yli-Halla, M. 1997. Quality of the ryegrass and lettuce yields as affected by selenium fertilization. Journal of Agricultural and Food Science 6: 381-387.

Hartikainen, H. \& Xue, T. 1999. The promotive effect of selenium on plant growth as triggered by UV irradiation. Journal of Environmental Quality 28: 1372-1375. https://doi.org/10.2134/jeq1999.00472425002800040043x

Hoewyk, D., van Takahashi, H., Inoue, E., Hess, A., Tamaoki, M. \& Pilon-Smits, E.A.H. 2008. Transcriptome analyses give insights into selenium-stress responses and selenium tolerance mechanisms in Arabidopsis. Physiologia Plantarum 132: 236-253.

Kumpulainen, J., Raittila, A.M., Lehto, J. \& Koivistoinen, P. 1983. Electrochemical atomic absorption spectrometric determination of selenium in foods and diets. Journal of Association of Official Analytical Chemistry 66: 1129-1135.

LeDuc, D.L., Turun, A.S., Móntes-Bayon, M., Meija, J., Malit, M.F., Wu, C.P., AbdelSamie, M., Chiang, C.Y., Tagmount, A., deSouza, M., Neuhierl, B., Böck, A., Caruso, J. \& Terry, N. 2004. Overexpression of selenocysteine methyltransferase in Arabidopsis and indian mustard increases selenium tolerance and accumulation. Plant Physiology 135: 377-383. https://doi.org/10.1104/pp.103.026989

LeDuc, D.L., AbdelSamie, M., Móntes-Bayon, M., Wu, C.P., Reisinger, S.J. \& Terry, N. 2006. Overexpression of both ATP sulfurylase and selenocysteine methyltransferase enhances selenium phytomediation traits in indian mustard. Environmental Pollutant 144: 70-76. https://doi.org/10.1016/j.envpol.2006.01.008

Leustek, T. \& Saito, K. 1999. Sulfate transport and assimilation in plants. Plant Physiology 120: 637-643. https://doi.org/10.1104/ pp.120.3.637

Li, H.F., McGrath, S.P. \& Zhao, F.J. 2008. Selenium uptake, translocation and speciation in wheat supplied with SeVI and selenite. New Phytologist 178: 92-102. https://doi.org/10.1111/j.1469-8137.2007.02343.x

Li, X., Wu, Y., Li, B., Yang, Y. \& Yang, Y. 2018. Selenium accumulation characteristics and biofortification potentiality in turnip (Brassica rapa var. rapa) supplied with selenite or selenate. Frontiers in Plant Science 8: 2207. https://doi.org/10.3389/fpls.2017.02207

Livak, K.J. \& Schmittgen, T.D. 2001. Analysis of relative gene expression data using real-time quantitative PCR and the 2(-Delta Delta C (T)). Methods 25: 402-408. https://doi.org/10.1006/meth.2001.1262

Lyi, S.M., Zhou, X., Kochian, L.V. \& Li, L. 2007. Biochemical and molecular characterization of the homocysteine S-methyltransferase from broccoli (Brassica oleracea var. italica). Phytochemistry 68: 1112-1119. https://doi.org/10.1016/j.phytochem.2007.02.007

Lyons, G.H., Stangoulis, J.C.R. \& Graham, R.D. 2005. Tolerance of wheat (Triticum aestivum L.) to high soil and solution selenium levels. Plant and Soil 270: 179-188. https://doi.org/10.1007/s11104-004-1390-1

Lyons, G.H., Gene, Y., Soole, K., Stangoulis, J.C.R., Liu, F. \& Graham, R.D. 2009. Selenium increases seed production in Brassica. Plant and Soil 318: 73-80. https://doi.org/10.1007/s11104-008-9818-7

Mudd, S.H. \& Datko, A.H. 1990. The S-methylmethionine cycle in Lemna paucicostata. Plant Physiology 93: 623-630. https://doi. org/10.1104/pp.93.2.623

Neuhierl, B. \& Bock, A. 1996. On the mechanisms of selenium tolerance in selenium-accumulating plants: purification and characterization of a specific selenocysteine methyltransferase from cultured cells of Astragalus bisulcatus. European Journal of Biochemistry 239: 235-238. https://doi.org/10.1111/j.1432-1033.1996.0235u.x

Pilon-Smits, E.A.H., Hwang, S., Lythe, C.M., Zhu, Y., Tai, J.C., Bravo, R.C., Chen, Y., Leustek, T. \& Terry, N. 1999. Overexpression of ATP sulfurylase in Indian mustard leads to increased SeVI uptake, reduction, and tolerance. Plant Physiology 119: 123-132. https://doi.org/10.1104/pp.119.1.123

Ranocha, P., Bourgis, F., Ziemak, M.J., Rhodes, D., Gage, D.A. \& Hanson, A.D. 2001. The S-methylmethionine cycle in angiosperms: uniquity, antiquity and activity. Plant Journal 25: 575-584. https://doi.org/10.1046/j.1365-313x.2001.00988.x

Rayman, M. 2008a. Food-chain selenium and human health: spotlight on speciation. British Journal of Nutrition 100: 238-253. https://doi.org/10.1017/S0007114508922522

Rayman, M. 2008b. Food-chain selenium and human health: emphases on intake. British Journal of Nutrition 100: 254-268. https://doi.org/10.1017/S0007114508939830 
Renosto, F., Hamang, C.P., Martin, R.L., Thomassian, C., Zimmerman, G. \& Segel, H. 1993. ATP sulfurylase from higher plants: kinetic and structural characterization of the chloroplast and cytosol enzymes from spinach leaf. Archive of Biochemistry and Biophysics 307: 272-285. https://doi.org/10.1006/abbi.1993.1590

Seppänen, M.M., Kontturi, J., Lopez-Heras, I., Madrid, Y., Camara, C. \& Hartikainen, H. 2010. Agronomic biofortification of Brassica with Selenium - enrichment of SeMet and its identification in Brassica seeds and meal. Plant and Soil 337:273-283. https:// doi.org/10.1007/s11104-010-0523-y

Sors, T.G., Ellis, D.R. \& Salt, D.E. 2005a. Selenium uptake, translocation, assimilation and metabolic fate in plants. Photosynthesis Research 86: 373-389. https://doi.org/10.1007/s11120-005-5222-9

Sors, T.G., Ellis, D.R., Na, G.N., Lahner, B., Lee, S., Leustek, T., Pickering, I.J. \& Salt, D.E. 2005b. Analysis of sulfur and selenium assimilation in Astragalus plants with varying capacities to accumulate selenium. Plant Journal 42: 785-797. https://doi.org/10.1111/ j.1365-313X.2005.02413.X

Sors, T.G., Martin, C.P. \& Salt, D.E. 2009. Characterization of selenocysteine methyltransferases from Astragalus species with contrasting selenium accumulation capacity. Plant Journal 59: 110-122. https://doi.org/10.1111/j.1365-313X.2009.03855.x

Terry, N., Zayed, A.M., de Souza, M.P. \& Tarun, A.S. 2000. Selenium in higher plants. Annual Review of Plant Physiology and Plant Molecular Biology 51: 401-432. https://doi.org/10.1146/annurev.arplant.51.1.401

Vauclare, P., Kopriva, S., Fell, D., Suter, M., Sticher, L., von Ballmoos, P., Krähenbühl, U., Op den Camp, R. \& Brunold, C. 2002. Flux control of sulphate assimilation in Arabidopsis thaliana adenosine 5'-phosphosulphate eductase is more susceptible than ATP sulphurylase to negative control of thiols. Plant Journal 31: 729-740. https://doi.org/10.1046/j.1365-313X.2002.01391.x

White, P.J., \& Broadley, M.R. 2009. Biofortification of crops with seven mineral elements often lacking in human diets: iron, zinc, copper, calcium, magnesium, selenium and iodine. New Phytologist 182: 49-84. https://doi.org/10.1111/j.1469-8137.2008.02738.x

Xue, T., Hartikainen, H. \& Piironen, V. 2001. Antioxidative and growth-promoting effect of selenium on senescing lettuce. Plant and Soil 237: 55-61. https://doi.org/10.1023/A:1013369804867

Zhang, L.H., Abdel-Ghany, S.E., Freeman, A.R., Schiavon, M. \& Pilon-Smits, E.A.H. 2006. Investigation of selenium tolerance mechanisms in Arabidopsis thaliana. Physiologia Plantarum 128: 212-223. https://doi.org/10.1111/j.1399-3054.2006.00739.x 